\title{
BDNF mediated TrkB activation is a survival signal for transitional cell carcinoma cells
}

\author{
YEN TA HUANG ${ }^{1,3,4}$, PEI CHUN LAI ${ }^{1,5}$, CHIA CHEN WU ${ }^{6}$, SHIH HSIN HSU ${ }^{1}$, \\ CHUAN CHU CHENG ${ }^{6}$, YI FAN LAN ${ }^{1}$ and TED H. CHIU ${ }^{1,2}$ \\ ${ }^{1}$ Institute of Pharmacology and Toxicology, ${ }^{2}$ Department of Pharmacology, Tzu Chi University, Hualien 970; \\ ${ }^{3}$ Department of Emergency Medicine, ${ }^{4}$ Division of Surgical Critical Care Unit, Departments of ${ }^{5}$ Pediatrics \\ and ${ }^{6}$ Research, Buddhist Tzu Chi General Hospital, Hualien 970, Taiwan, R.O.C.
}

Received January 7, 2010; Accepted February 25, 2010

DOI: 10.3892/ijo_00000633

\begin{abstract}
Pathologically, $>90 \%$ of bladder cancer is transitional cell carcinoma (TCC). Previously, brain-derived neurotrophic factor (BDNF) but not tropomyosin-related kinase B (TrkB) was found in normal urothelium. TrkB activation by BDNF has been shown to promote the progression of several cancers, however, the existence and functional roles of both BDNF and TrkB in TCC have not been elucidated. In this study, three human TCC cell lines, BFTC905, TSGH8301, and T24 were used for the investigation. Both BDNF and TrkB but not TrkA or TrkC identified by RT-PCR and Western blotting were found in these cell lines. Immunostaining demonstrated the cytosolic expression of BDNF and TrkB, as well as membranous expression of TrkB in these cells. BDNF released from three cell lines was also detected in culture medium by ELISA. The proliferation of BFTC905 cells was enhanced by recombinant human BDNF (rhBDNF) in vitro, which was associated with increased phospho-TrkB and phospho-ERK levels. In contrast, TrkB-Fc chimeric protein served as BDNF scavenger eliciting cytotoxicity. Addition of rhBDNF in these cell lines cultured in poly-HEMA [Poly(2-hydroxyethyl methacrylate)] coated dishes for $48 \mathrm{~h}$ did not confer resistance to anoikis. Increased phospho-Akt expression was observed transiently within an hour after rhBDNF administration but disappeared $24 \mathrm{~h}$ later. Weekly injections of $100 \mathrm{ng}$ rhBDNF into the cancer cell-loading site for 6 weeks promoted BFTC905 xenograft growth in SCID mice. Daily injection of $5 \mu \mathrm{g}$ TrkB-Fc chimeric protein into the tumor 2 weeks after tumor cell implantation delayed tumor growth concomitant with phospho-TrkB suppression in xenografts. These results indicate that BDNF binding to TrkB receptor is
\end{abstract}

Correspondence to: Dr Ted H. Chiu, Institute of Pharmacology and Toxicology, Tzu Chi University, Chung Yang Rd., Hualien 970, Taiwan, R.O.C.

E-mail: thchiu@mail.tcu.edu.tw

Key words: BDNF, TrkB, bladder cancer, transitional cell carcinoma, xenograft a survival signal for TCC cells. Drugs that block BDNF or TrkB may provide a new and potential approach for TCC therapy.

\section{Introduction}

Bladder cancer is one of the most commonly diagnosed malignancies in the world (1). Pathologically, $>90 \%$ of bladder cancer is transitional cell carcinoma (TCC). Current therapies for bladder cancer include surgery, radiation, and/or chemotherapy (2). However, the median survival time is approximately one year once distant metastasis occurs, despite aggressive treatment (3). Research should therefore direct toward new strategies for bladder cancer treatment.

BDNF (brain-derived neurotrophic factor) is a member of the neurotrophin family. BDNF exerts its effects by binding to the tyrosine kinase receptor $\operatorname{TrkB}$ (tropomyosin-related kinase $\mathrm{B}$ ), which regulates neuronal survival and differentiation (4). TrkB has also been found in many normal non-neuronal tissues, such as macrophages, and epidermis (5). BDNF but not TrkB has also been found in normal urothelium, but the function of BDNF in urothelium remains unclear $(5,6)$. In cancer biology, BDNF and/or TrkB have also been found in several malignant tissues, e.g., neuroblastoma (7), pancreatic ductal adenocarcinoma (8), prostate cancer (9), lung cancer (10), and hepatocellular carcinoma (HCC) (11). TrkB has also been demonstrated to mediate resistance to anoikis, apoptosis resulting from the loss of cell-matrix interaction (12). This phenomenon may result from the activation of the PI3K-AKT pathway in ovarian cancer cells (13). The neurotrophin receptor family TrkA and TrkC also mediate the progression of some tumors (14-17), but their expressions in normal urothelium and TCC have not been reported. Results from this study provide the first evidence that BDNF and TrkB are survival factors in TCC, indicating that these targets may be exploited for clinical therapy.

\section{Materials and methods}

Cell culture and anoikis assay. Three human TCC cell lines were chosen for the investigation, i.e., BFTC905 and TSGH8301 from Taiwanese TCC patients $(18,19)$, and T24 
from ATCC, with the grading of 3 and 2, and 2/3, respectively. They were provided by Dr Jui-I Chao (Department of Biological Science and Technology, National Chiao Tung University, Hsin-Chu, Taiwan), and the cells were maintained as described previously (20). For anoikis study, 24-well dishes were pre-coated with 5 or $10 \mathrm{mg} / \mathrm{ml}$ poly-HEMA [poly(2hydroxyethyl methacrylate), Sigma, St. Louis, MO], and the cells will survive under suspension culture conditions if they exhibit the ability of anoikis resistance.

Cell growth and MTT cytotoxicity assay. Growth of $8 \times 10^{5}$ BFTC905 cells were plated in $10 \mathrm{~cm}$ dish containing RPMImedium supplemented with $1 \%$ fetal bovine serum (FBS) plus 0-20 nM rhBDNF (recombinant human BDNF, Calbiochem, Merck KGaA, Darmstadt, Germany) (day 0). Subsequently, the cells were re-cultured with fresh medium plus rhBDNF on days 2 and 4 . Cell counts were calculated by a hemocytometer on days 2,4 , and 6 . For anoikis study, $1 \times 10^{4}$ TCC cells were cultured in poly-HEMA coated dishes with $1 \%$ or $10 \%$ FBS plus 0-50 nM rhBDNF for $48 \mathrm{~h}$. Subsequently, cells were collected and stained with trypan blue (Sigma), and only live cells were counted in the hemocytometer.

For cytotoxic effect, 1x104 BFTC905 cells per well were seeded in 96-well plates. Recombinant human TrkB-Fc chimeric protein (R\&D Systems, Minneapolis, MN) at 0$20 \mu \mathrm{g} / \mathrm{ml}$ was added to the medium containing $1 \%$ FBS for 72 h. Human immunoglobulin (IgG, Sigma) treatment was served as a negative control. Conventional MTT (methylthiazolyldiphenyl-tetrazolium bromide, Sigma) assay was followed (20).

Mouse xenograft model. The NOD.CB17-Prkdc ${ }^{\text {scid}} /$ Tcu (SCID) male mice, 3-4 weeks of age, were provided and cared by the Laboratory Animal Center of Tzu Chi University. Preliminary data showed that, among the 3 cell line examined, only BFTC905 cells grew successfully and consistently in these mice, and hence only BFTC905 xenograft was studied. One million BFTC905 cells in $500 \mu$ l PBS (phosphate-buffered saline) was implanted s.c. into the right inguinal area of the mice (day 0). Starting on day 0, $100 \mathrm{ng}$ rhBDNF in $50 \mu \mathrm{l}$ distilled water or distilled water (control) were injected s.c. weekly for 6 weeks into the loading site of cancer cells or directly into the tumor when it became palpable. Tumor dimensions were measured weekly and the tumor volumes were calculated using the formula: [1/2] $\mathrm{x} a \times b^{2}$, where $a$ and $b$ represent the larger and smaller tumor diameters, respectively. Mice were sacrificed and the xenografts were removed after one 6-week treatment, and liver/lung/peritoneum were also checked for possible metastases.

In another study, $5 \mu \mathrm{g}$ of recombinant human TrkB-Fc chimeric protein or human IgG dissolved separately in $50 \mu \mathrm{l}$ PBS, or $50 \mu 1$ normal saline, were administered s.c. daily similar to those of rhBDNF. The first day of drug injection was started on day 14 after tumor cells implantation, and the mice were sacrificed on day 35 .

Immunocytochemistry (ICC). Cancer cells were fixed on the gelatin-coated slides with methanol (Riedel-deHaen, SigmaAldrich, Seelze, Germany) at $-20^{\circ} \mathrm{C}$ for $5 \mathrm{~min}$, and then dried in room air. For membranous staining only, cancer cells on
Table I. Primer sequences of BDNF, TrkA, TrkB, TrkC, and GAPDH.

$\mathrm{BDNF}^{1}$ (743 transcripts)

Forward 5'-ATGACCATCCTTTTCCTTACTATG-3'

Reverse 5'-CTATCTTCCCCTTTTAATGGTCAA-3'

$\mathrm{BDNF}^{2}$ (480 transcripts)

Forward 5'-GGGTTTATCTTTTGAGAACTTTTG-3'

Reverse 5'-CTTTTGCTTATCCCTCACCCTACT-3'

$\operatorname{TrkB}^{1}$ (401 transcripts)

Forward 5'-TGTCCCACGTCCTGCAAATGCAGT-3'

Reverse 5'-GCCTCTTGGAGAGTCTTGATCCAC-3'

$\operatorname{TrkB}^{2}$ (600 transcripts)

Forward 5'-TATCTATGGGAGATTAAAACCAGA-3'

Reverse 5'-TGCACACAAGGTATTAATCGACGA-3'

$\operatorname{TrkA}^{1}$ (413 transcripts)

Forward 5'-GCACTGAAGGAGGCGTCCGAGAGT-3'

Reverse 5'-ACGGTAATAGTCGGTGCTGTAGAT-3'

$\operatorname{TrkA}^{2}$ (179 transcripts)

Forward 5'-CGGAATACTGGGGCCTGCCCTCAG-3'

Reverse 5'-TTTCAAGGGATAATAAATATAATT-3'

$\operatorname{TrkC}^{1}$ (240 transcripts)

Forward 5'-CGGCCGGACGATGGGAACCTCTTC-3'

Reverse 5'-GTTCTTGGCAAAGGCTCTGGGCTG-3'

$\operatorname{TrkC}^{2}$ (120 transcripts)

Forward 5'-AATTCAT=ACTCTGTTGCCTCCTCT-3'

Reverse 5'-TGTATGTGTAGCAGGCACTTGAGT-3'

GAPDH (306 transcripts)

Forward 5'-CGGAGTCAACGGATTTGGTCGTAT-3'

Reverse 5'-AGCCTTCTCCATGGTGGTGAAGAC-3'

These sequences are derived from the mRNA of human BDNF transcript variant 1, Genbank accession no. NM_170735; TrkB transcript variant a, NM_006180; TrkA transcript variant 1, NM_001012331; TrkC transcript variant 1, NM_001012338; and GAPDH, NM_002046.

gelatin-coated slides were fixed with $4 \%$ paraformaldehyde (Riedel-deHaen) at $37^{\circ} \mathrm{C}$ for $2 \mathrm{~h}$. Further steps of immunostaining used by Department of Pathology, Buddhist Tzu Chi General Hospital were followed (21). Primary antibodies of anti-BDNF (sc-546, Santa Cruz Biotechnology Inc., Santa Cruz, CA), anti-TrkB (sc-8316, Santa Cruz), anti-TrkA (AF175, R\&D Systems), and anti-TrkC (AF373, R\&D Systems) were used. Exclusion of primary antibody was used as a negative control.

Enzyme-linked immunosorbent assay (ELISA). Human BDNF Quantikine $^{\mathrm{TM}}$ and human phospho-TrkB DuoSet ${ }^{\mathrm{TM}}$ ELISA 


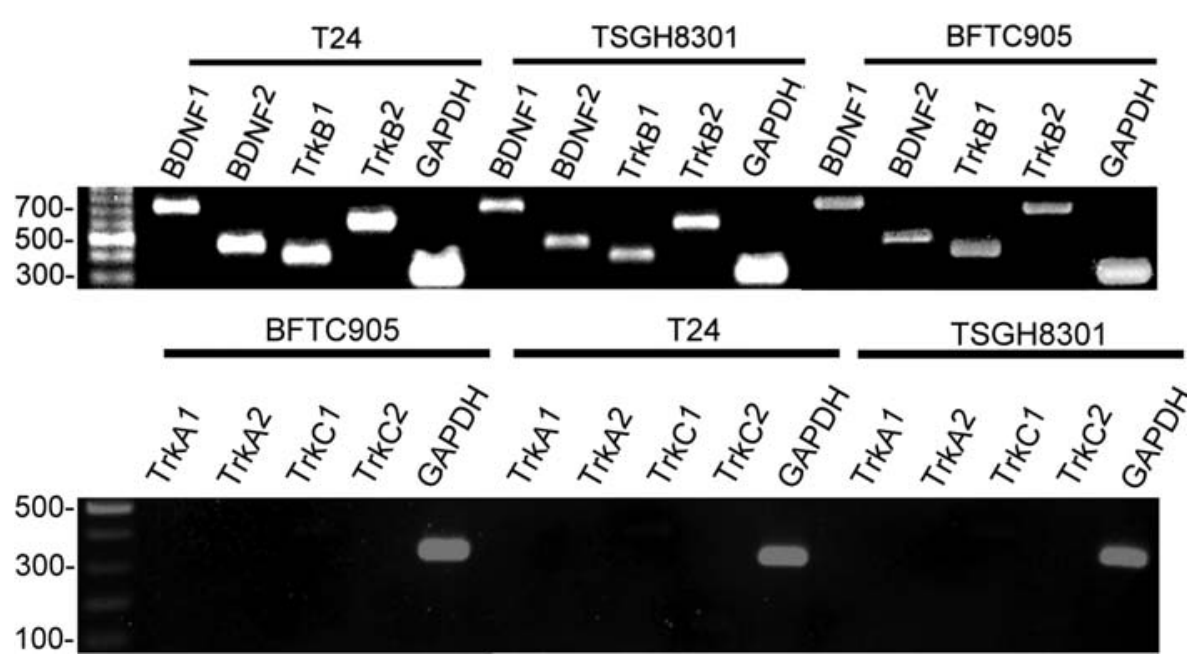

Figure 1. TrkB and BDNF mRNA expression in bladder cancer cells. BDNF and TrkB mRNAs were measured by RT-PCR in T24, TSGH8301 and BFTC905 bladder cancer cell lines. TrkA or TrkC mRNAs were not detected. Primers of BDNF ${ }^{1} / \mathrm{TrkB}^{1}$ and $\mathrm{BDNF}^{2} / \mathrm{TrkB}^{2}$ were designed from the coding and $3^{\prime}$ untranslated regions, respectively, of each mRNA sequence. TrkA $1 / \operatorname{TrkA}^{2}$ and $\operatorname{TrkC}^{1} / \operatorname{TrkC}^{2}$ were also designed under the same principle. GADPH mRNA was used as a positive control.

kit purchased from R\&D Systems were used. BDNF secretion was measured from $5 \times 10^{7}$ cells incubated in $10 \mathrm{ml}$ medium plus $10 \% \mathrm{FBS}$ for $24 \mathrm{~h}$. After centrifugation, the supernatants were filtered through Amicon Ultra centrifugal filter devices (10K \& 50K Da cut off, Millipore, Billerica, MA) to remove interfering proteins. For phospho-TrkB detection, BFTC905 cells $\left(1 \times 10^{7}\right)$ were treated with PBS or $20 \mathrm{nM}$ rhBDNF for 0-30 min or after initial overnight treatment with $0.5 \mu \mathrm{g} / \mathrm{ml}$ of TrkB Ab or IgG followed by $20 \mathrm{nM}$ rhBDNF for $30 \mathrm{~min}$. Phospho-TrkB levels in xenograft were measured $2 \mathrm{~h}$ after the last daily injection of a 21-day TrkB-Fc chimeric protein treatment. The procedures recommended by the manufacturer were followed.

Reverse transcription-polymerase chain reaction (RT-PCR). $\mathrm{BDNF}^{1}$ and $\mathrm{BDNF}^{2}$ primers from coding and non-coding region, respectively (Protec Technology, Taipei, Taiwan), and similarly TrkA, TrkB and TrkC primers were designed to check the mRNA levels using RT-PCR. GAPDH (glyceraldehyde-3-phosphate dehydrogenase) mRNA was used as an internal control. The primer sequences are shown in Table I. RT-PCR steps as used previously were followed (22). A total of 39 PCR cycles under sequential settings of $95^{\circ} \mathrm{C}$ for $1 \mathrm{~min}$, $57^{\circ} \mathrm{C}$ for $1 \mathrm{~min}$ and $72^{\circ} \mathrm{C}$ for $1 \mathrm{~min}$ was used.

Western blot analysis. Standard procedures were followed (20). Primary antibodies used included anti-BDNF, anti-TrkB, anti-TrkA, anti-TrkC, phospho-ERK (extracellular related kinase, \#9106, Cell Signaling, Danvers, MA), and phosphoAKT (\#4051, Cell Signaling). Expression of ERK2 (sc-154, Santa Cruz), AKT (sc-8312, Santa Cruz), or actin (sc-1616, Santa Cruz) was used as the internal standard. Phosphorylated protein signals were augmented by Can Get Signal ${ }^{\mathrm{TM}}$ immunostain (Toyobo, Osaka, Japan). The intensity of immunoreactive proteins was scanned and the intensity calculated by NIH software ImageJ V.1.40.

Statistical analysis. Data are expressed as mean \pm SEM (standard error of mean) and evaluated by Student's t-test, one-way or two-way ANOVA based on individual data. In all cases, $\mathrm{p}<0.05$ was considered statistically significant and labeled by an asterisk on the figures.

\section{Results}

BDNF and TrkB were expressed in TCC cells. Nucleotide sequences from database reveal that BDNF, TrkB, TrkA and TrkC possess large untranslated sequences. Thus, 2 sets of primers, one from the coding region and the other from the 3' untranslated region, were designed to estimate the mRNA levels using RT-PCR. Both coding and non-coding regions of BDNF and TrkB but not TrkA and TrkC mRNA fragments were expressed in 3 TCC cell lines (Fig. 1). Both pro-BDNF and BDNF protein were expressed in these cell lines (Fig. 2A). Only TrkB (both full-length and truncated, 145 and $95 \mathrm{kDa}$, respectively) but not TrkA or TrkC immunoreactive proteins were found in these cell lines (Fig. 2B-D). TrkB (95 and $145 \mathrm{kDa})$ proteins were also found in BFTC905 xenograft tissue (Fig. 2B).

Immunocytochemical analysis of three cell lines (Fig. 3) demonstrated BDNF protein expression in the cytoplasm of cells under methanol fixation, which disrupted cell membrane, allowing primary antibody to penetrate into the cytoplasm. However, DAB stained cells were not observed if bladder cancer cells were fixed with paraformaldehyde, which maintained an intact plasma membrane. These results confirmed the cytoplasmic localization of BDNF in human bladder cancer cells. No DAB stains were found when primary antibody was eliminated from the reaction mixture (control panel). In addition to the presence in the cytoplasm, BDNF release $(150.8 \pm 46.1,93.6 \pm 60.5$, and $193.3 \pm 50.6 \mathrm{pg} / \mathrm{ml}$ for BFTC905, TSGH8301, and T24, respectively; $\mathrm{n}=3$ ) was also detected in culture medium by ELISA assay. No BDNF was detected in the culture medium contaning $10 \%$ FBS without cells. Furthermore, TrkB protein expression was found in the cytosol plus cytosol/plasma membrane under methanol fixation but was observed only on the plasma membrane under paraformaldehyde fixation (Fig. 3). This demonstrated 

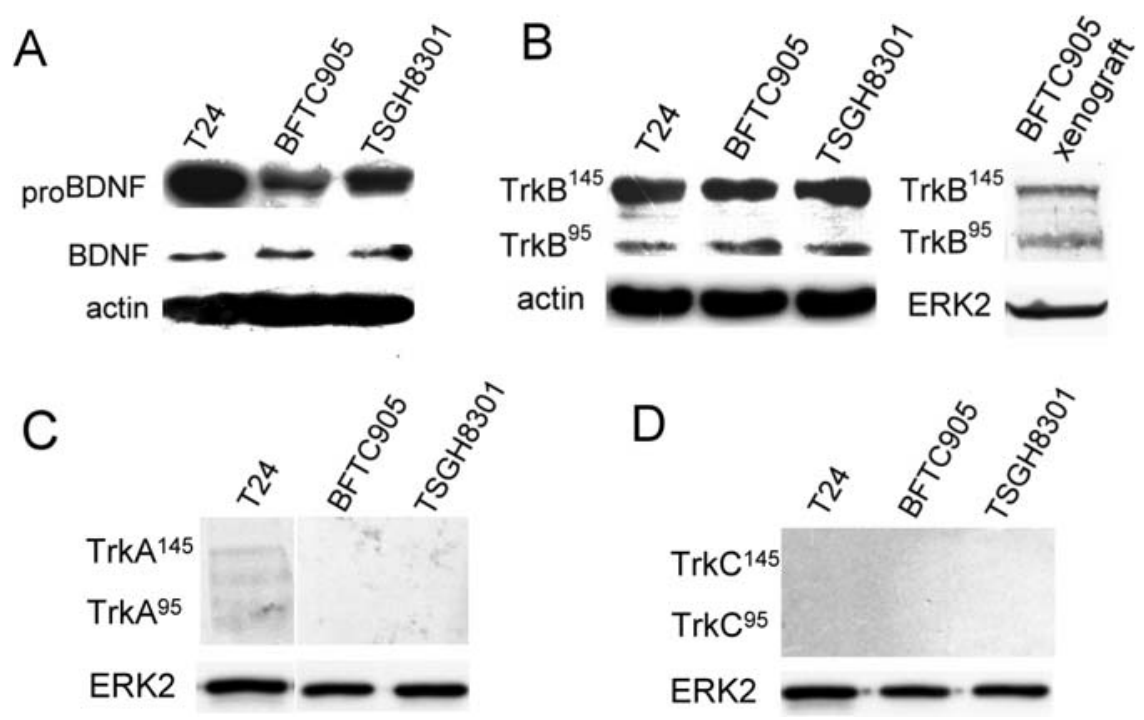

Figure 2. TrkB and BDNF immunoreactive protein expression in bladder cancer cells and the xenograft tumor. Presence of (A) pro-BDNF protein (30 kDa) and BDNF protein (14 kDa) and (B) the full length (TrkB145) and truncated (TrkB95) TrkB; absence of (C) TrkA and (D) TrkC proteins detected by Western blotting. Actin or ERK2 expression was used as the internal standard.

that TrkB existed both in cytosol and on plasma membrane of human bladder cancer cells. Results revealed neither TrkA nor TrkC expression in these cell lines.

BDNF promoted BFTC905 cell survival but did not resist anoikis, while recombinant human TrkB-Fc chimeric protein induced cytotoxicity in vitro. Consistent xenograft tumor formation was observed only after BFTC905 cell implantation, thus BFTC905 cells were chosen for further in vitro studies. Fig. 4A shows that $20 \mathrm{nM}$ rhBDNF significantly enhanced BFTC905 cell proliferation with the medium containing $1 \%$ FBS ( $p=0.02$, two-way ANOVA). ELISA showed that phosphorylated TrkB protein was significantly elevated $10 \mathrm{~min}$ after the addition of $20 \mathrm{nM}$ rhBDNF and persisted for at least $30 \mathrm{~min}$ (Fig. 4B, p=0.02, n=4). The rhBDNF-induced phospho-TrkB expression was blocked when cells were pre-treated overnight with $0.5 \mu \mathrm{g} / \mathrm{ml} \mathrm{TrkB}$ $\mathrm{Ab}$ (Fig. 4B). ERK activation is one of the signaling pathways of TrkB activation (23), and it mediates TrkB-induced cancer progression (24). Importantly, ERK activation predicts poor outcome in TCC patients (25). Thus, we examined the dynamic expression of phospho-ERK after rhBDNF stimulation in BFTC905 cells. Increased expression of phospho-ERK was also observed after $20 \mathrm{nM}$ rhBDNF administration (Fig. 4C).

The effect of a BDNF scavenger, recombinant human TrkB-Fc chimeric protein, was investigated to substantiate the functional interaction between the endogenous BDNF and TrkB. TrkB-Fc chimeric protein elicited significant cytotoxicity under serum-deprived conditions with the medium containing $1 \%$ FBS (Fig. 4D). Cultured after $48 \mathrm{~h}$ in both 5 and $10 \mathrm{mg} / \mathrm{ml}$ poly-HEMA coated dishes, all TCC cells in the presence of 0-50 nM rhBDNF showed nuclear trypan blue staining (data not shown). Consequently these TCC cell lines did not exhibit the ability to resist anoikis despite exogenous BDNF administration. The time-course of the expression of phospho-AKT after $50 \mathrm{nM}$ rhBDNF administration in BFTC905 cells maintained in poly-HEMA coated dishes showed increased expression after $1 \mathrm{~h}$ but disappeared $24 \mathrm{~h}$ later (Fig. 4E).

BDNF promoted while recombinat human TrkB-Fc chimeric protein suppressed the growth of BFTC 905 xenograft tumor. Among the 3 cell lines examined, only BFTC905 cells grew successfully and consistently in SCID mice. No gross liver or lung metastases were observed. Fig. 5A shows that weekly injection of $100 \mathrm{ng}$ rhBDNF accelerated tumor growth reflected in significantly increased tumor volume (Fig. 5A, n=21-22, $\mathrm{p}=0.04$, two-way ANOVA). Tumor volumes of $678.4 \pm 136.6$ and $1024.0 \pm 133.0 \mathrm{~mm}^{3}$ were found for control and rhBDNFtreated tumor respectively after 6-week implantation. Fig. 5B demonstrates that $5 \mu \mathrm{g}$ TrkB-Fc chimeric protein administered s.c. on day 14 after tumor cell implantation suppressed the tumor growth after 3 weeks of treatments ( $p=0.04$, two-way ANOVA). IgG did not affect the growth of xenografts compared to saline control (IgG V.S. N/S, p=0.33, two-way ANOVA). The expression of phospho-TrkB in xenografts was reduced after TrkB-Fc treatment, measured by ELISA $(\mathrm{n}=5, \mathrm{p}=0.02$, Fig. $5 \mathrm{C})$.

\section{Discussion}

The present study demonstrated the existence of BDNF and TrkB in three TCC cell lines. The exogenous rhBDNF promoted bladder cancer growth in vitro and in vivo. We have also shown that rhBDNF activated the phosphorylation of TrkB and its downstream signaling molecule ERK in vitro. The expression of phospho-TrkB protein was blocked by TrkB-Fc chimeric protein. The growth and the level of phospho-TrkB in xenograft tumors were suppressed by TrkB-Fc treatment. These results are the first observations to demonstrate that the activation of TrkB by BDNF and the subsequent phosphorylation of TrkB and ERK play important roles in TCC growth.

As expected, TrkB receptor is a plasma membrane protein, but cytoplasmic expression has been also observed in normal 


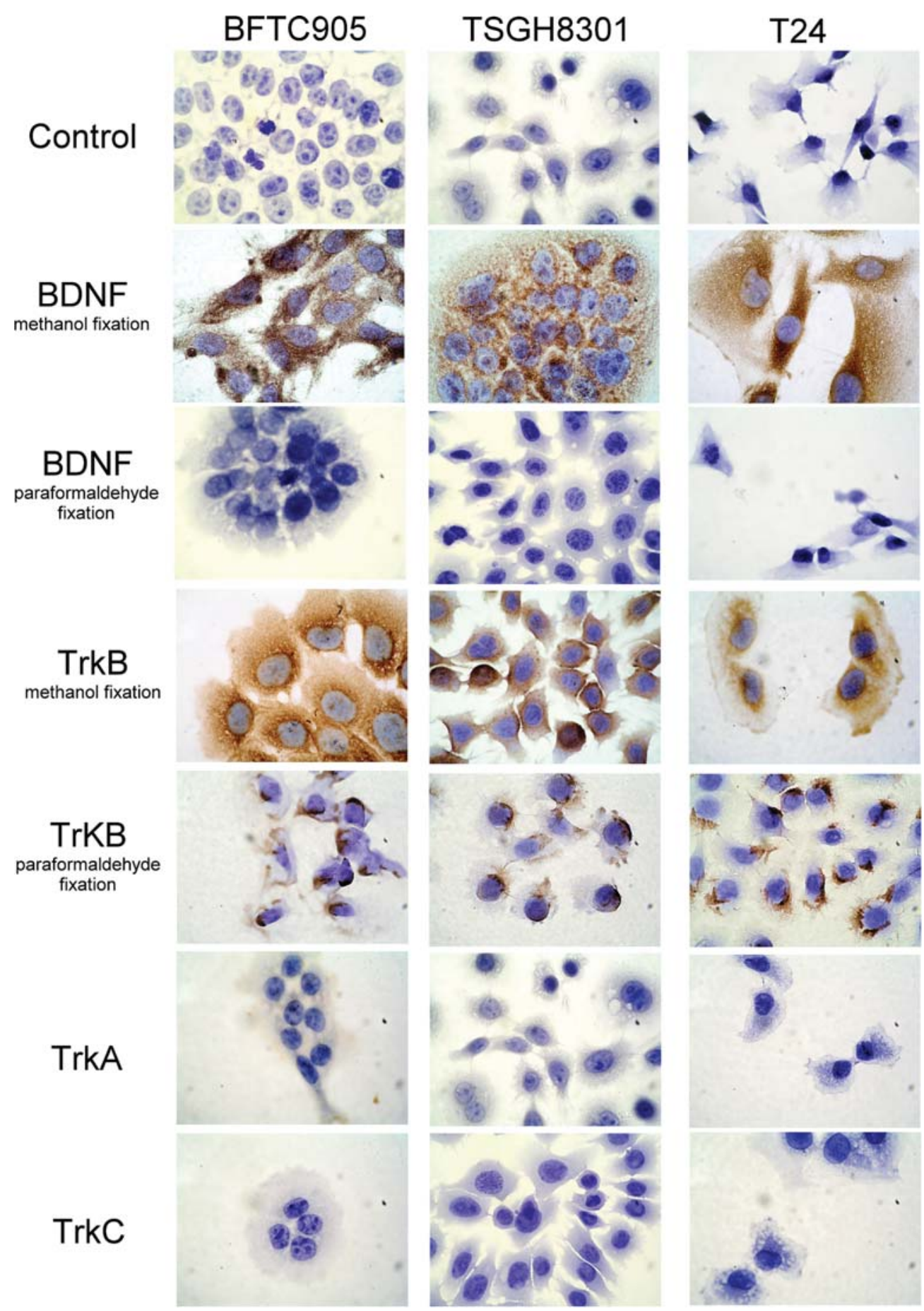

Figure 3. Immunostaining localization of BDNF and TrkB expression in TCC cells. Target proteins were stained brown with DAB. Nuclei were counterstained blue with hematoxylin. Cytoplasmic expression of BDNF and TrkB proteins was detected under methanol fixation, which disrupted the membrane, allowing the primary antibody to penetrate into the cytoplasm. Membranous expression of TrkB was detected under paraformaldehyde fixation, which maintained an intact plasma membrane and the primary antibody cannot penetrate into the cytoplasm. Immunostainings of BDNF and TrkB, but not TrkA or TrkC were detected in 3 TCC cell lines (x1000).

cells $(26,27)$, ovarian cancer cells $(13)$, as well as TCC cells in our study. However, the function of cytosolic TrkB requires further investigation. Although TrkB, TrkA or TrkC has been found to mediate certain tumor progression (14-17), our results indicate that neither mRNA nor protein expression of TrkA or TrkC can be detected in TCC. These data demonstrate the absence and the lack of functional roles of TrkA and TrkC in bladder cancer cells, further strengthening the importance of BDNF and TrkB in bladder cancer growth. Importantly, previous studies reported that TrkB has not been found in normal urothelium (5), so TrkB blockade might be a specific target for TCC with no physiological influence on normal urothelium.

Evaluation of the cellular growth cultured in poly-HEMA coated dishes is an established method to observe the cellular death by anoikis (28). Anoikis resistance mediates the survival 
A

B
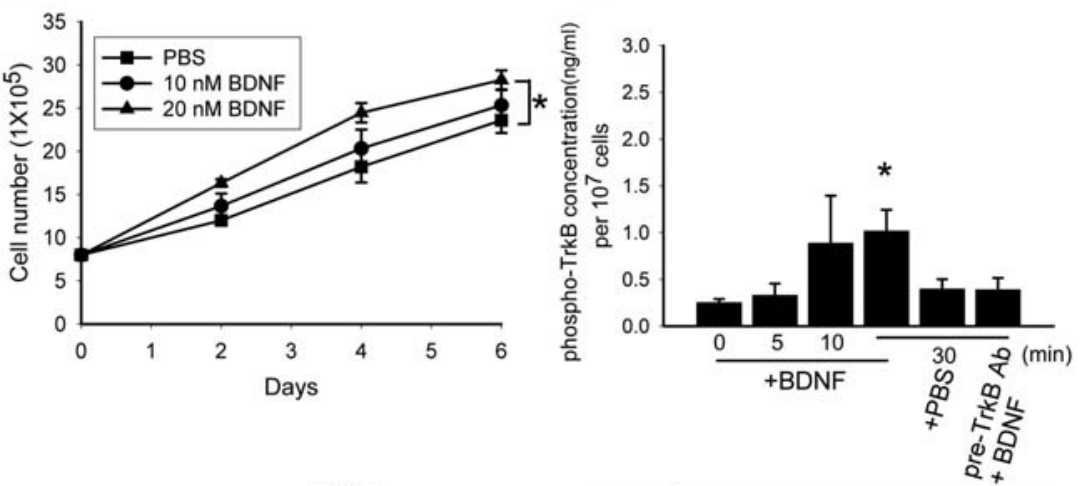

C

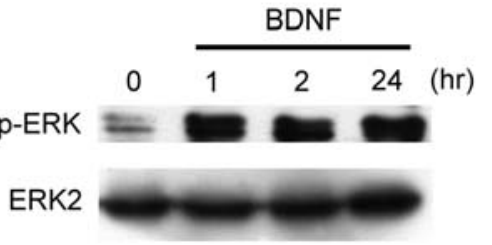

E
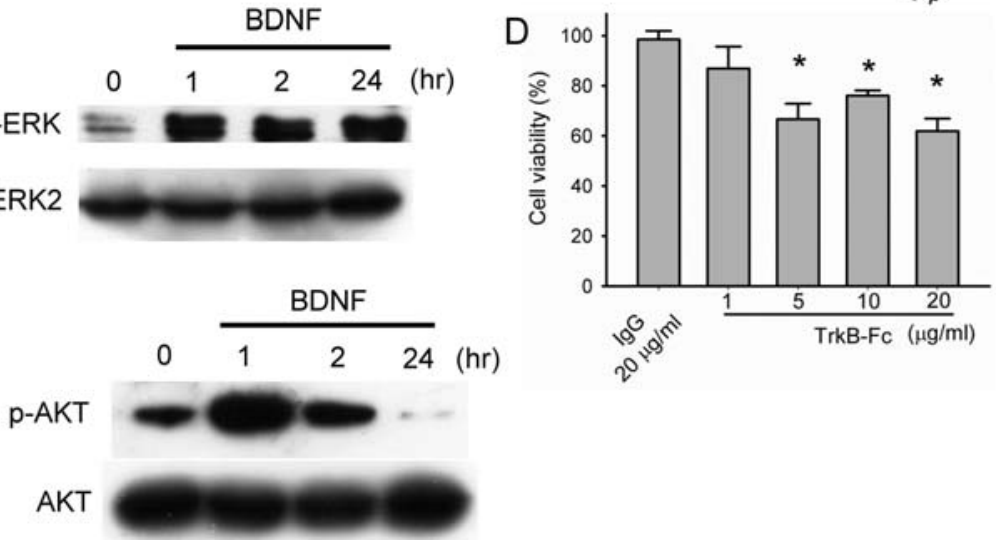

Figure 4. Effects of exogenous rhBDNF on BFTC905 cells in vitro. (A) BFTC905 cells cultured in undernourished medium (1\% FBS) were treated with 10 or $20 \mathrm{nM}$ rhBDNF. Cell proliferation during 6-day incubation was obtained. " $\mathrm{p}<0.05$. (B) Time course of exogenous $20 \mathrm{nM}$ rhBDNF stimulation on the expression of phospho-TrkB was obtained by ELISA. Pre-treatment with $0.5 \mu \mathrm{g} / \mathrm{ml}$ of TrkB Ab for $24 \mathrm{~h}$ blocked the stimulating effect of $20 \mathrm{nM}$ BDNF. "p $<0.05$ compared to the absence of BDNF. (C) Time course of phospho-ERK expression after $20 \mathrm{nM}$ rhBDNF activation. (D) Cytotoxic effect of TrkB-Fc was measured by MTT assay $72 \mathrm{~h}$ after treatment. Cell viability of IgG treatment was set as $100 \%$. " $\mathrm{p}<0.05 \mathrm{vs}$ IgG treatment. (E) Time course of phospho-AKT expression after $50 \mathrm{nM}$ rhBDNF activation cultured in poly-HEMA dishes.

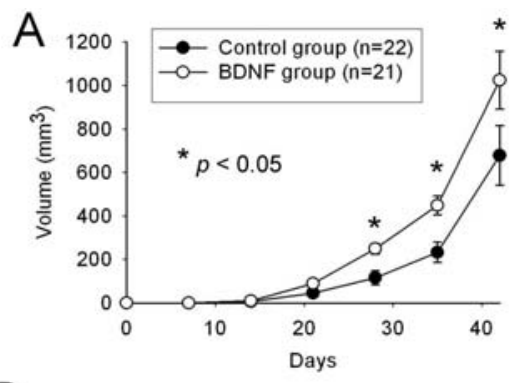

B
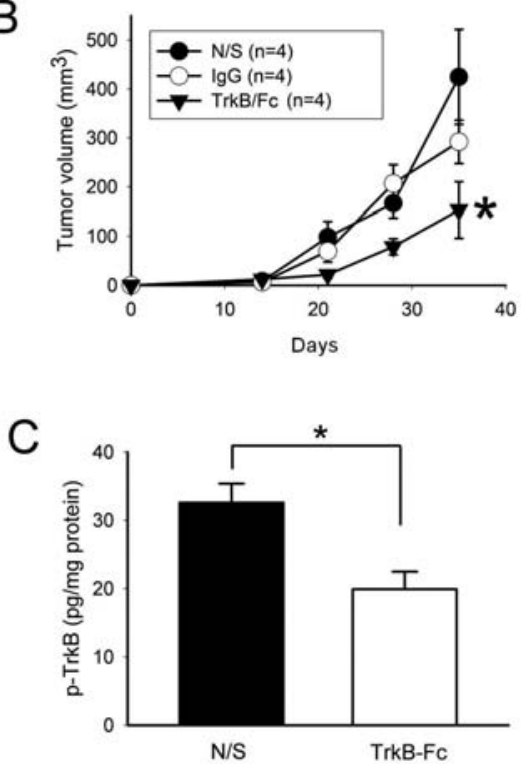

of cancer cells detached from extracellular matrix with multiple signaling pathways including BDNF-TrkB axis, and further promotes metastasis (29). Although both BDNF and TrkB were expressed in BFTC905, T24, and TSGH8301 cells, these TCC cells did not resist anoikis in the polyHEMA dishes. Besides, exogenous rhBDNF did not improve the survival in this suspension culture condition despite transient AKT activation. These results indicated that BDNF and TrkB do not rescue these 3 TCC cell lines from anoikis in such culture system. Only one previous study mentioned the ability of anoikis resistance in TCC cells through COX-2 (cyclooxygenase 2) transfection into human bladder cancer cell line EJ, also under poly-HEMA culture conditions (30). Maybe poly-HEMA coated dish is not suitable for anoikis resistance study in TCC cells, and other

Figure 5. Growth of BFTC905 xenografts in vivo. (A) $100 \mathrm{ng}$ rhBDNF in $50 \mu 1$ distilled water was injected subcutaneously into the loading site of cancer cells once a week, starting the day following cancer cell injection. A total of five rhBDNF administrations was given. The tumor volumes were calculated using the formula: [1/2] $\mathrm{x} a \mathrm{x} b^{2}$, where $a$ and $b$ represent the larger and smaller tumor diameters, respectively. (B) Recombinant human TrkB-Fc chimeric protein at $5 \mu \mathrm{g} / 50 \mu \mathrm{l}$ PBS was administered s.c. daily into the loading site of cancer cells or directly into the tumor starting on day 14 after implantation. Similar administration of $50 \mu 1$ normal saline (N/S) or human $\mathrm{IgG}$ at $5 \mu \mathrm{g} / 50 \mu \mathrm{l}$ PBS served as the control. (C) Expression of phospho-TrkB in xenograft after 21-day TrkB-Fc treatment was measured by ELISA. 
methodology such as culture dish with ultra-low attachment coated polystyrene surface may be used for further investigation (31).

Among the three cell lines tested, only BFTC905 cells successfully grew in SCID mice. Subcutaneous xenografts for T24 (32) and TSGH8301 (33) in SCID mice have been reported. However, these studies chose higher tumor cell loading ( $4 \times 10^{6}$ and $1 \times 10^{7}$, for T24 and TSGH8301, respectively) compared to our study $\left(1.0 \times 10^{6}\right)$, so consequently tumor masses might grow more quickly and easily. The characteristics of microenvironment on invasiveness for three cell lines might differ, resulting in different speeds of mass formation (32). Besides, the IgG leakage in SCID mice might be another problem (34). The percentage of IgG leakage in SCID mice might be different between our study and the previous reports. In the present study, xenografts of BFTC905 cells consistently grew under condition of less tumor cell loading compared to previous studies. This result indicates that BFTC905 cell line might be a better candidate for in vivo TCC study.

Exogenous BDNF promoted TCC cell growth only under serum-deprived medium containing $1 \% \mathrm{FBS}$, but without proliferative effect in 10\% FBS medium (unpublished data). Similarly, Pearse et al (35) demonstrated that BDNF promoted the survival of multiple myeloma cells without stroma. Yang et al (11) also showed that BDNF significantly enhanced the proliferating properties of HCC cells. We anticipated that the effects of exogenous BDNF would emerge from a more stressful environment, which was demonstrated in the medium containing $1 \%$ FBS.

Detectable BDNF in culture media confirmed its autocrine existence in TCC cells. Furthermore, phosphorylation of TrkB was observed in the absence of exogenous rhBDNF, and the cytotoxicity appeared after scavenging BDNF with TrkB-Fc established the autocrine function of BDNF. In addition to its autocrine origin, circulating BDNF elaborated by certain cells or tissues may also exist. Thus, in vivo BDNF administration into mice may reflect enhanced paracrine release of BDNF to promote the growth of bladder cancer xenografts. Yang et al (11) detected increased levels of serum and plasma BDNF in HCC. They further showed that activated $\mathrm{CD}^{2} \mathrm{P}^{+}$and $\mathrm{TrkB}^{+}$platelets as important sources for storing BDNF (36), suggesting that the origin of BDNF other than tumor cells may affect tumor progression.

The recombinant human TrkB-Fc chimeric protein is composed of the extracellular domain of human TrkB fused to the $\mathrm{C}$-terminal histidine tagged $\mathrm{Fc}$ region of human $\operatorname{IgG}_{1}$, allowing it to specifically bind human BDNF. TrkB-Fc sequesters BDNF and consequently functions as a specific TrkB inhibitor (37-39). Blockade of BDNF/TrkB interaction by TrkB-Fc delayed the progression of the xenograft bladder tumor in SCID mice through inhibition of TrkB phosphorylation. We also found that pan-Trk inhibitor K252a also suppressed BFTC905 xenograft tumor growth (unpublished data). Therefore, the blocking of TrkB receptor may become a new strategy for bladder cancer therapy.

Recent reports have demonstrated the important roles of BDNF/TrkB in cancer progression $(40,41)$. Oral Trk inhibitor CEP-701, which also inhibits TrkB (42), has been evaluated in a clinical trial (43). We found the existence of BDNF and
TrkB in TCC cell lines. Exogenous BDNF promoted TCC xenograft growth, and BDNF ablation elicited opposite effects. These results indicate that BDNF and TrkB receptor play important roles in regulating TCC growth. Targeting the BDNF or TrkB receptor may provide an important new approach for treating TCC.

\section{Acknowledgments}

The authors would like to thank the generous assistance of Ms. Wen Chi Su, Drs Yun Hsiang Hsu and Jui-I Chao. This study was partially supported by a grant from NSC (NSC-972314-B-303-016, YTH), Taiwan and grant-in-aid from Tzu Chi University (THC) and Tzu Chi General Hospital (YTH), Hualien 970, Taiwan.

\section{References}

1. Parkin D: The global burden of urinary bladder cancer. Scand J Urol Nephrol 218: 12-20, 2008.

2. Bellmunt J, Albiol S, Suarez C and Albanell J: Optimizing therapeutic strategies in advanced bladder cancer: update on chemotherapy and the role of targeted agents. Criti Rev Oncol Hematol 69: 211-222, 2009.

3. Calabro F and Sternberg CN: High-risk metastatic urothelial cancer: chances for cure? Curr Opin Urol 12: 441-448, 2002.

4. Huang EJ and Reichardt LF: Neurotrophins: roles in neuronal development and function. Annu Rev Neurosci 24: 677-736, 2001.

5. Shibayama E and Koizumi H: Cellular localization of the Trk neurotrophin receptor family in human non-neuronal tissues. Am J Pathol 148: 1807-1818, 1996.

6. Lommatzsch M, Braun A, Mannsfeldt A, Botchkarev VA, Botchkareva NV, Paus R, Fischer A, Lewin GR and Renz H: Abundant production of brain-derived neurotrophic factor by adult visceral epithelia. Implications for paracrine and targetderived neurotrophic functions. Am J Pathol 155: 1183-1193, 1999.

7. Aoyama M, Asaib K, Shishikurac T, Kawamoto T, Miyachi T, Yokoi T, Togari H, Wada Y, Kato T and Nakagawara A: Human neuroblastomas with unfavorable biologies express high levels of brain-derived neurotrophic factor mRNA and a variety of its variants. Cancer Lett 164: 51-60, 2001.

8. Miknyoczki SJ, Lang D, Huang L, Klein-Szanto AJ, Dionne CA and Ruggeri BA: Neurotrophins and Trk receptors in human pancreatic ductal adenocarcinoma: expression patterns and effects on in vitro invasive behavior. Int J Cancer 81: 417-427, 1999.

9. Montano X and Djamgoz MB: Epidermal growth factor, neurotrophins and the metastatic cascade in prostate cancer. FEBS Lett 571: 1-8, 2004.

10. Ricci A, Greco S, Mariotta S, Felici L, Bronzetti E, Cavazzana A, Cardillo G, Amenta F, Bisetti A and Barbolini G: Neurotrophins and neurotrophin receptors in human lung cancer. Am J Respir Cell Mol Biol 25: 439-446, 2001.

11. Yang ZF, Ho DW, Lam CT, Luk JM, Lum CT, Yu WC, Poon RT and Fan ST: Identification of brain-derived neurotrophic factor as a novel functional protein in hepatocellular carcinoma. Cancer Res 65: 219-225, 2005.

12. Douma S, Van Laar T, Zevenhoven J, Meuwissen R, van Garderen E and Peeper DS: Suppression of anoikis and induction of metastasis by the neurotrophic receptor TrkB. Nature 430: 1034-1039, 2004.

13. Yu X, Liu L, Cai B, He Y and Wan X: Suppression of anoikis by the neurotrophic receptor TrkB in human ovarian cancer. Cancer Sci 99: 543-552, 2008.

14. Nakagawara A: Trk receptor tyrosine kinases: a bridge between cancer and neural development (review). Cancer Lett 169: 107-114, 2001.

15. Pierotti MA and Greco A: Oncogenic rearrangements of the NTRK1/NGF receptor (review). Cancer Lett 232: 90-98, 2006.

16. Dollé L, Adriaenssens E, El Yazidi-Belkoura I, Le Bourhis X, Nurcombe $\mathrm{V}$ and Hondermarck $\mathrm{H}$ : Nerve growth factor receptors and signaling in breast cancer (review). Curr Cancer Drug Targets 4: 463-470, 2004. 
17. Brodeur GM, Minturn JE, Ho R, Simpson AM, Iyer R, Varela CR, Light JE, Kolla V and Evans AE: Trk receptor expression and inhibition in neuroblastomas (review). Clin Cancer Res 15 3244-3250, 2009.

18. Tzeng CC, Liu HS, Li C, Jin YT, Chen RM, Yang WH and Lin JS: Characterization of two urothelium cancer cell lines derived from a blackfoot disease endemic area in Taiwan. Anticancer Res 16: 1797-1804, 1996.

19. Yeh MY, Yu DS, Chen SC, Lin MS, Chang SY, Ma CP and Han SH: Establishment and characterization of a human urinary bladder carcinoma cell line (TSGH-8301). J Surg Oncol 37 : 177-184, 1988

20. Chao JI, Su WC and Liu HF: Baicalein induces cancer cell death and proliferation retardation by the inhibition of CDC2 kinase and survivin associated with opposite role of p38 mitogen-activated protein kinase and AKT. Mol Cancer Ther 6: 3039-3048, 2007.

21. Liu YN, Liu Y, Lee HJ, Hsu YH and Chen JH: Activated androgen receptor downregulates E-cadherin gene expression and promotes tumor metastasis. Mol Cell Biol 28: 7096-7108, 2008.

22. Chao JI, Kuo PC and Hsu TS: Down-regulation of survivin in nitric oxide-induced cell growth inhibition and apoptosis of the human lung carcinoma cells. J Biol Chem 279: 20267-20276, 2004.

23. Slack SE, Grist J, Mac Q, McMahon SB and Pezet S: TrkB expression and phospho-ERK activation by brain-derived neurotrophic factor in rat spinothalamic tract neurons. J Comp Neurol 489: 59-68, 2005.

24. Sugimoto T, Kuroda H, Horii Y, Moritake H, Tanaka T and Hattori S: Signal transduction pathways through TRK-A and TRK-B receptors in human neuroblastoma cells. Jpn J Cancer Res 92: 152-160, 2001.

25. Karlou M, Saetta AA, Korkolopoulou P, Levidou G, Papanastasiou P, Boltetsou E, Isaiadis D, Pavlopoulos P, Thymara I, Thomas-Tsagli E and Patsouris E: Activation of extracellular regulated kinases (ERK1/2) predicts poor prognosis in urothelial bladder carcinoma and is not associated with B-Raf gene mutations. Pathology 41: 327-334, 2009.

26. Anger DL, Zhang B, Boutross-Tadross O and Foster WG: Tyrosine receptor kinase $\mathrm{B}$ (TrkB) protein expression in the human endometrium. Endocrine 31: 167-173, 2007.

27. Iwabe S, Moreno-Mendoza NA, Trigo-Tavera F, Crowder C and Garcia-Sanchez GA: Retrograde axonal transport obstruction of brain-derived neurotrophic factor (BDNF) and its TrkB receptor in the retina and optic nerve of American Cocker Spaniel dogs with spontaneous glaucoma. Vet Ophthalmol 10: 12-19, 2007.

28. Bretland AJ, Lawry J and Sharrard RM: A study of death by anoikis in cultured epithelial cells. Cell Prolif 34: 199-210, 2001.

29. Simpson CD, Anyiwe K and Schimmer AD. Anoikis resistance and tumor metastasis (review). Cancer Lett 272: 177-185, 2008.
30. Choi EM, Kwak SJ, Kim YM, Ha KS, Kim JI, Lee SW and Han JA: COX-2 inhibits anoikis by activation of the PI-3K/Akt pathway in human bladder cancer cells. Exp Mol Med 37: 199-203, 2005.

31. Uehara N, Matsuoka Y and Tsubura A: Mesothelin promotes anchorage-independent growth and prevents anoikis via extracellular signal-regulated kinase signaling pathway in human breast cancer cells. Mol Cancer Res 6: 186-193, 2008.

32. Bindels EM, Vermey M, De Both NJ and van der Kwast TH: Influence of the microenvironment on invasiveness of human bladder carcinoma cell lines. Virchows Arch 439: 552-559, 2001.

33. Su SJ, Yeh TM, Lei HY and Chow NH: The potential of soybean foods as a chemoprevention approach for human urinary tract cancer. Clin Cancer Res 6: 230-236, 2000.

34. Albert SE, McKerlie C, Pester A, Edgell BJ, Carlyle J, Petric M and Chamberlain JW: Time-dependent induction of protective anti-influenza immune responses in human peripheral blood lymphocyte/SCID mice. J Immunol 159: 1393-1403, 1997.

35. Pearse RN, Swendeman SL, Li Y, Rafii D and Hempstead BL: A neurotrophin axis in myeloma: TrkB and BDNF promote tumor-cell survival. Blood 105: 4429-4436, 2005.

36. Yang ZF, Ho DW, Lau CK, Tam KH, Lam CT, Poon RT and Fan ST: Platelet activation during tumor development, the potential role of BDNF-TrkB autocrine loop. Biochem Biophys Res Commun 346: 981-985, 2006.

37. Binder DK, Routbort MJ, Ryan TE, Yancopoulos GD and McNamara JO: Selective inhibition of kindling development by intraventricular administration of TrkB receptor body. J Neurosci 19: 1424-1436, 1999.

38. Miletic G and Miletic V: Loose ligation of the sciatic nerve is associated with TrkB receptor-dependent decreases in KCC2 protein levels in the ipsilateral spinal dorsal horn. Pain 137: 532-539, 2008.

39. Yajima Y, Narita M, Usui A, Kaneko C, Miyatake M, Narita M, Yamaguchi T, Tamaki H, Wachi H, Seyama Y and Suzuki T: Direct evidence for the involvement of brain-derived neurotrophic factor in the development of a neuropathic pain-like state in mice. J Neurochem 93: 584-594, 2005.

40. Geiger TR and Peeper DS: Critical role for TrkB kinase function in anoikis suppression, tumorigenesis, and metastasis (review). Cancer Res 67: 6221-6229, 2007.

41. Thiele CJ, Li Z and McKee AE: On Trk-the TrkB signal transduction pathway is an increasingly important target in cancer biology (review). Clin Cancer Res 15: 5962-5967, 2009.

42. Festuccia C, Muzi P, Gravina GL, Millimaggi D, Speca S, Dolo V, Ricevuto E, Vicentini C and Bologna M: Tyrosine kinase inhibitor CEP-701 blocks the NTRK1/NGF receptor and limits the invasive capability of prostate cancer cells in vitro. Int J Oncol 30: 193-200, 2007.

43. Chan E, Mulkerin D, Rothenberg M, Holen KD, Lockhart AC, Thomas J and Berlin J: A phase I trial of CEP-701 + gemcitabine in patients with advanced adenocarcinoma of the pancreas. Invest New Drugs 26: 241-247, 2008. 